\title{
Association between bone scan index and activities of daily living in patients with advanced non-small cell lung cancer: methodological issues in cross-sectional study
}

\author{
Fatemeh Khosravi Shadmani $^{1}$ - Shiva Mansouri Hanis ${ }^{2} \cdot$ Kamyar Mansori $^{3,4}$
}

Received: 23 March 2017 / Accepted: 12 June 2017 / Published online: 25 June 2017

(C) Springer-Verlag GmbH Germany 2017

Dear Editor-in-Chief,

We read, with great interest, the paper written by Ikuno Ito et al. entitle association between bone scan index and activities of daily living in patients with advanced non-small cell lung cancer that was published in 2017. The authors aimed to study the association between the bone scan index (BSI) and activities of daily living (ADL) in patients with advanced nonsmall cell lung cancer (NSCLC). It was concluded that a higher value of the BSI $(\geq 1.0)$ is an independent predictor of poor ADL in patients with advanced NSCLC [1]. However, although this was a valuable investigation and its findings were very interesting, some methodological issues should be considered.

First, Suzanne Ikuno Ito et al. [1] evaluated the predictor of elevated higher value of the BSI $(\geq 1.0)$ in a cross-sectional study, whereas longitudinal studies are most important for

Kamyar Mansori

kamyarmansori@yahoo.com

1 Department of Epidemiology, School of Public Health, Shahid Beheshti University of Medical Sciences, Tehran, Iran

2 School of Public Health, Dezful University of Medical Sciences, Dezful, Iran

3 Social Development and Health Promotion Research Center, Gonabad University of Medical Sciences, Gonabad, Iran

4 Department of Epidemiology, School of Public Health, Iran University of Medical Sciences, Tehran, Iran making assumptions for clinical prediction models [2]. In other words, the temporality assumption (the dependent variable has to occur after the independent variable) must be ensured in the prediction model. Thus, prediction models resulting from cross-sectional designs can be misleading [2-4].

Second, if variable of higher value of the BSI $(\geq 1.0)$ is considered as independent predictor, then elevated ALT is an optimistic interpretation. The internal and external validation of the prediction model must be done through bootstrapping and split-validation, respectively [5]. Therefore, according to the above explanation, it is necessary to take these points into consideration at the time of interpretation of results of this study for readers.

\section{References}

1. Ito I, Ito K, Takahashi S, Horibe M, Karita R, Nishizaka C et al (2017) Association between bone scan index and activities of daily living in patients with advanced non-small cell lung cancer. Support Care Cancer: $1-7$

2. Steyerberg E. Clinical prediction models: a practical approach to development, validation, and updating: Springer Science and Business Media; 2008.

3. Ayubi E, Sani M (2016) Carotid atherosclerosis is associated with left ventricular diastolic function: methodological issue. J Echocardiogr 14(4):181

4. Mansori K, Mansouri Hanis S, Shadmani FK. (2017) Postpartum modern contraceptive use and associated factors in northern Ethiopia: methodological issues in this cross-sectional study. Korean J Epidemiol:e2017019

5. Noto D, Cefalù A, Barbagallo C, Ganci A, Cavera G, Fayer F et al (2016) Baseline metabolic disturbances and the twenty-five years risk of incident cancer in a Mediterranean population. Nutr Metab Cardiovasc Dis 26(11):1020-1025 